\title{
Match running performance in Brazilian professional soccer players: comparisons between successful and unsuccessful teams
}

\author{
Rodrigo Aquino 1,2, Luiz Guilherme Gonçalves ${ }^{3}$, Marcos Galgaro ${ }^{4}$, Thiago Santi Maria ${ }^{5}$, Eduardo Rostaiser ${ }^{5}$, \\ Alejandro Pastor ${ }^{5}$, Hadi Nobari ${ }^{6,7^{*}}$, Gabriel Rodrigues Garcia ${ }^{1}$, Maxwell Viana Moraes-Neto ${ }^{1}$ and \\ Fábio Yuzo Nakamura ${ }^{8}$
}

\begin{abstract}
Background: This study aimed to compare the match running performance between bottom- and top-ranked teams in professional soccer players over the 2020 season of the Brazilian National 2nd Division League. In addition, this study verified the independent and interactive effects of playing position and contextual factors on running outputs between these teams.

Methods: Forty-eight professional male outfield soccer players participated in this study (top-ranked team, $n=24$; bottom-ranked team, $n=24)$. The distance- and accelerometry-based measures were recorded during 69 matches using a global positioning system $(10 \mathrm{~Hz})$ integrated with an accelerometer $(400 \mathrm{~Hz})$.

Results: The top-ranked team covered greater total distance [median (interquartile range); 10,330.0 m (1430.0)] and high-acceleration [97.0 $\mathrm{m}$ (32.0)] than the bottom-ranked team, in home and away matches $[p<0.05$, effect size $(E S)=$ small]. The midfielders of the top-ranked team covered higher total distance, high-speed running $\left(>18 \mathrm{~km} \mathrm{~h}^{-1}\right)$, high acceleration $\left(\geq 3 \mathrm{~m} \mathrm{~s}^{-2}\right)$, high-deceleration $\left(\leq-3 \mathrm{~m} \mathrm{~s}^{-2}\right)$, and performed more sprints $\left[\left(>25 \mathrm{~km} \mathrm{~h}^{-1}\right)\right.$ compared to midfielders of the bottom-ranked team $\left(p<0.05, n^{2}=\right.$ small-moderate]. The matches against top-level opponents required high values of high-acceleration and number of sprints only for the top-ranked team $(p<0.05, \mathrm{ES}=$ small). Independent analysis showed that match outcome (loss vs. draw vs. win) was not influenced by running performance for both bottom- and top-ranked teams $\left(p>0.05 ; \eta^{2}=\right.$ small). However, the top-ranked team covered greater total distance, high-acceleration/deceleration than bottom-ranked team in loss matches $\left(p<0.05, \eta^{2}=\right.$ small).

Conclusions: These findings should be considered when the coaches and practitioners interpret the match running outputs and when evaluating the effects of training intervention on these performance indicators.
\end{abstract}

Keywords: Sports science, Match analysis, Contextual factors, Performance, Team sports

*Correspondence: hadi.nobari1@gmail.com

${ }^{6}$ Department of Exercise Physiology, Faculty of Sport Sciences, University of Isfahan, 81746-7344 Isfahan, Iran

Full list of author information is available at the end of the article

\section{Introduction}

Researchers and practitioners' interest in the physical performance of soccer players during the match-play using distance-based measures (e.g., distance covered at different speeds) has grown substantially over the last five decades, leading to a myriad of studies and systematic and scientific evidence-based approaches to physical conditioning [1-3]. In addition, global positioning original author(s) and the source, provide a link to the Creative Commons licence, and indicate if changes were made. The images or other third party material in this article are included in the article's Creative Commons licence, unless indicated otherwise in a credit line to the material. If material is not included in the article's Creative Commons licence and your intended use is not permitted by statutory regulation or exceeds the permitted use, you will need to obtain permission directly from the copyright holder. To view a copy of this licence, visit http://creativecommons.org/licenses/by/4.0/. The Creative Commons Public Domain Dedication waiver (http://creativeco mmons.org/publicdomain/zero/1.0/) applies to the data made available in this article, unless otherwise stated in a credit line to the data. 
systems (GPS) units are commonly equipped with accelerometers or inertial sensor units (IMUs), which makes it possible to obtain distance- and accelerometry-based data (e.g., acceleration/deceleration) simultaneously [4, 5]. However, there are some issues related to the use and interpretation of measures derived from GPS [6, 7]. For example, some measures (e.g., total distance covered and distance in high-speed running) can be highly dependent on positional role, tactical contexts, players' physical fitness, competitive standard, and contextual factors, among other aspects $[4,8-10]$. On the other hand, the investigation of accelerometry-derived measures in response to the aforementioned independent variables should be better investigated during the match play. In fact, many teams still use semiautomatic camera systems during the matches [11], and it can provide only limited information about competition mechanical load.

The extensive coverage of this research agenda on match running performance has forcibly shaped contemporary opinions with researchers and practitioners frequently emphasizing the position and context and their links with match outcomes [1, 12, 13]. Classic studies reported that players' fitness levels and competitive physical performance at professional standards were superior to those observed in peers at lower-competitive standards $[14,15]$, suggesting that the match physical component discriminates the best teams and players from their less competitive counterparts. However, previous studies in professional Leagues in England [16, 17], Italy [18], and Brazil [9] demonstrated that lower distances were covered in higher compared to lower standard divisions and teams' ranking, with substantial variations across some specific playing positions [19]. In contrast, studies in La Liga [20] and German Bundesliga [21] demonstrated that running performance does not affect the teams' success as defined by the position on the table, indicating the necessity of further studies in different leagues of the world. In addition, there is a need to improve the current holistic approach to data analysis of top- and the bottom-ranked teams of the same season by evaluating interactions between match running performance and other factors, including the playing positions and contextual variables (e.g., match location, quality of opposition, match outcome). This analysis could provide comprehensive information on the factors that can affect running demands during the match-play in successful and unsuccessful teams.

Therefore, this study aimed to compare the match running performance between bottom-ranked and top-ranked teams over the 2020 season of the Brazilian National 2nd Division League. In addition, this study verified the independent and interactive effects of playing position and contextual factors on running outputs between these teams. We expected that a top-ranked team present greater physical demands than the bottomranked counterparts. In addition, we expected that playing position and contextual factors impact the running performance.

\section{Material and methods Study design}

This study was conducted under non-experimental conditions in which the research problem was embedded [22]. The players' running performance was quantified during the matches over the 2020 season of the Brazilian National 2nd Division League. This League was disputed by 20 soccer clubs, of which the top four had access to 1st Division of 2021 and the last four were relegated to 3rd Division of 2021. Originally, the League was scheduled to start on May 2 of 2020, and to end on 28 November of 2020. However, due to the COVID-19 pandemic, its beginning was rescheduled for August 7 of 2020, and the new closure on January 29, 2021.

The present study analyzed the season of one successful team (top-four ranking and access to 1st Division of 2021; $\mathrm{n}=31$ matches; $\mathrm{n}=166$ individual observations) and one unsuccessful team (last-four ranking and relegated to 3rd Division of 2021; $\mathrm{n}=38$ matches; $\mathrm{n}=228$ individual observations) (Table 1). Five analyses were performed: (1) general results, comparisons of the running outputs between top-and bottom-ranked teams (1st halves vs. 2nd halves vs. whole matches); (2) independent and interactive effects of playing positions (i.e., central defenders, external defenders, midfielders, forwards) and teams' ranking on running performance; (3) independent and interactive effects of match location (i.e., home, away) and teams' ranking on running performance; (4) independent and interactive effects of quality of opposition (i.e., bottom-level [16th-20th in the current ranking], intermediate-level [5th-15th in the current ranking], top-level [1st-4th in the current ranking]) and teams' ranking on running performance; (5) independent and interactive effects of match outcome (i.e., loss, draw, win) and teams' ranking on running performance.

\section{Participants}

Forty-eight professional male outfield soccer players participated in this study, including 24 players of top-ranked team (age $28 \pm 5 \mathrm{yrs}$; height $180 \pm 5 \mathrm{~cm}$; body mass $78 \pm 8 \mathrm{~kg}$; central defenders $=7$; external defenders $=5$; midfielders $=8$; forwards $=5$ ) and 24 players of bottomranked team (age $25 \pm 5$ yrs; height $179 \pm 8 \mathrm{~cm}$; body mass $79 \pm 9 \mathrm{~kg}$; central defenders $=6$; external defenders $=5$; midfielders $=7$; forwards $=6$ ). Inclusion required participation in $\geq 90 \mathrm{~min}$ of play. The study was approved by the local Human Research Ethics Committee (School 
Table 1 Information about the successful and unsuccessful teams analyzed in this study according to the final classification during the 2020 season of the Brazilian National 2nd Division League

\begin{tabular}{llllllll}
\hline Position & Team & Points & W & D & L & PI & \\
\hline 1 & Chapecoense & 73 & 20 & 13 & 5 & 38 & Access to the 2021 season of the Brazilian National 1st Division League \\
2 & América-MG & 73 & 20 & 13 & 5 & 38 & \\
3 & Juventude & 61 & 17 & 10 & 11 & 38 & \\
4 & Cuiabá & 61 & 17 & 10 & 11 & 38 & \\
5 & CSA & 58 & 16 & 10 & 12 & 38 & Maintenance to the 2021 season of the Brazilian National 2nd Division League \\
6 & Sampaio Corrêa & 57 & 17 & 6 & 15 & 38 & \\
7 & Ponte Preta & 57 & 16 & 9 & 13 & 38 & \\
8 & Operário & 57 & 15 & 12 & 11 & 38 & \\
9 & Avaí & 55 & 16 & 7 & 15 & 38 & \\
10 & CRB & 52 & 15 & 7 & 16 & 38 & \\
11 & Cruzeiro & 49 & 14 & 13 & 11 & 38 & \\
12 & Brasil de Pelotas & 49 & 11 & 16 & 11 & 38 & \\
13 & Guarani & 48 & 13 & 9 & 16 & 38 & \\
14 & EC Vitória & 48 & 11 & 15 & 12 & 38 & \\
15 & Confiança & 46 & 12 & 10 & 16 & 38 & \\
16 & Náutico & 44 & 10 & 14 & 14 & 38 & \\
17 & Figueirense & 39 & 9 & 12 & 17 & 38 \\
18 & Paraná & 37 & 9 & 10 & 19 & 38 \\
19 & Botafogo-SP & 34 & 8 & 10 & 20 & 38 \\
20 & Oeste & 29 & 7 & 8 & 23 & 38 & \\
\hline
\end{tabular}

$\mathrm{W}=$ matches won; $\mathrm{D}=$ matches Drawn; $\mathrm{L}=$ matches lost $\mathrm{PI}=$ played matches. Bold means the references teams analyzed in this study. Juventude = successful team; Botafogo-SP $=$ unsuccessful team

of Physical Education and Sport of Ribeirão Preto, University of São Paulo; protocol no. 61884716.9.0000.5659).

\section{Dependent measures}

The distance- and accelerometry-based measures were recorded in real-time during the matches using a wearable $10-\mathrm{Hz}$ GPS integrated with a $400-\mathrm{Hz}$ Tri-Axial accelerometer and $10-\mathrm{Hz}$ Tri-Axial magnetometer (Playertek, Catapult Innovations, Australia). The devices were fitted to the upper back of each player using adjustable harnesses and were activated $15 \mathrm{~min}$ before the data collection, in accordance with the manufacturer's instructions to optimize the acquisition of satellite signals. Previous studies analyzed data obtained from this system $[23,24]$. The players used the same device throughout the season to avoid inter-unit error [25]. The following metrics were obtained: (1) total distance covered (TD, m); (2) total distance covered under high-speed running (HSR, > $18 \mathrm{~km} \mathrm{~h}^{-1}, \mathrm{~m}$ ); (3) number of sprints $\left(>25 \mathrm{~km} \mathrm{~h}^{-1}\right)$; (4) total distance covered under highacceleration (Acc, $\geq 3 \mathrm{~m} \mathrm{~s}^{-2}, \mathrm{~m}$ ); (5) total distance covered under high-deceleration (Dec, $\left.\leq-3 \mathrm{~m} \mathrm{~s}^{-2}, \mathrm{~m}\right)$. The speed and accelerometry thresholds used are similar to those reported in previous studies $[23,24,26]$.

\section{Independent measures}

Four independent variables were considered for data analysis: (1) playing positions for each player for each match were determined by a Brazilian Soccer Confederation qualified coach and heatmap obtained of the GPS analysis (central defenders $[\mathrm{n}=136$ individual observations], external defenders $[\mathrm{n}=96$ individual observations], midfielders $[\mathrm{n}=100$ individual observations], forwards $[\mathrm{n}=61$ individual observations]. The tactical formation of the analyzed teams (e.g., 1-4-4-2 "diamond") and the playing position verified in the heatmap analysis did not allow to divide the midfielders into the two positions usually adopted: central and external; (2) match location (home [ $\mathrm{n}=205$ individual observations], away [ $\mathrm{n}=188$ individual observations]; (3) quality of opposition (bottom-level [ $\mathrm{n}=71$ individual observations]; intermediate-level [ $\mathrm{n}=250$ individual observations]; top-level $[\mathrm{n}=72$ individual observations]; (4) match outcome (loss $[\mathrm{n}=163$ individual observations], draw $[\mathrm{n}=107$ individual observations], win [ $\mathrm{n}=123$ individual observations]).

\section{Statistical analysis}

The Kolmogorov-Smirnov (general results) revealed that match running performance data were not normally 
distributed for some variables $(p<0.05)$. Thus, to avoid textual confusion, all the data are described by the median (interquartile range). The comparisons of running outputs between bottom- and top-ranked teams (general results) were assessed using the Mann-Whitney test. The ANOVA two-way was used to compare the interactive effects of independent measures on running performance: (1) playing position according to rankingteams; (2) match location according to ranking-teams; (3) quality of opposition according to team's ranking; (4) match outcome according to ranking-teams. The significance level was set at $p<0.05$. Data were analyzed using the SPSS for Windows statistical software package version 22.0 (SPSS Inc., Chicago, IL, USA). Additionally, effect sizes (ES) for non-parametric data (general results) were calculated for pairwise comparisons $(E S=\mathrm{z} / \sqrt{ } \mathrm{n})$ and classified as negligible $(<0.1)$, small $(0.1-0.29)$, medium (0.3-0.49), and large $(>0.5)$ [27]. The ES for parametric data (playing positions, match location, quality of opponents, match outcome) were assessed using partial eta squared $(\eta 2)$, and classified as: $>0.01$ (small), $>0.06$ (moderate), and $>0.15$ (large) [28].

\section{Results}

\section{General}

The top-ranked team presented greater TD and highacceleration during the 1st halves, 2 nd halves, and whole matches compared to bottom-ranked team $(p<0.001-$ 0.04; $\mathrm{ES}=$ small; Table 2)

\section{Playing positions}

External defenders $\left(\eta^{2}=\right.$ small $)$, midfielders $\left(\eta^{2}=\bmod -\right.$ erate), and forwards $\left(\eta^{2}=\right.$ small $)$ of the top-ranked team covered greater TD than bottom-ranked team $(p<0.001-0.004)$ (Fig. 1A). External defenders of topranked team also performed greater number of sprints $\left(\eta^{2}=\right.$ small; Fig. 1C) and high-deceleration $\left(p \eta^{2}=\right.$ small;
Fig. 1D) compared to bottom-ranked team $(p<0.001-$ $0.03)$. Midfielders of the top-ranked team showed greater HSR $\left(\eta^{2}=\right.$ small; Fig. $\left.1 B\right)$, number of sprints $\left(\eta^{2}=\right.$ small; Fig. $1 C)$, high-acceleration $\left(\eta^{2}=\right.$ moderate; Fig. $\left.1 \mathrm{E}\right)$, and high-deceleration $\left(\eta^{2}=\right.$ small; Fig. 1D) than bottomranked team $(p<0.001-0.003)$. In contrast, central defenders of the bottom-ranked team presented higher TD $\left(\eta^{2}=\right.$ small; Fig. 1A) and HSR $\left(\eta^{2}=\right.$ small; Fig. $\left.1 \mathrm{~B}\right)$ than top-ranked team $(p=0.002-0.004)$.

\section{Match location}

Interactive effects showed that home matches played by top-ranked team resulted in higher TD and highdeceleration compared to home matches played by bottom-ranked team $\left(p=0.01-0.02, \eta^{2}=\right.$ small; Table 3$)$. In addition, away matches played by top-ranked team showed greater TD and high-acceleration than away matches played by bottom-ranked team $(p=0.001-0.04$, $\eta^{2}=$ small.

\section{Quality of opposition}

Independent analysis showed that top-ranked team covered greater distance in high-acceleration and performed more sprints in matches against top-level opponents compared to bottom-level $\left(p=0.02-0.03, \eta^{2}=\right.$ small $)$ (Table 4). Interactive analysis demonstrated that the top-ranked team covered greater TD than the bottomranked team in matches against top-level and intermediate-level opponents $\left(p<0.001-0.009 ; \eta^{2}=\right.$ small $)$. Top-ranked team also presented higher values of highacceleration and high-deceleration than bottom-ranked team in matches against top-level opponents $(p<0.001$, $\eta^{2}=$ small).

\section{Match outcome}

Interactive analysis demonstrated that top-ranked team covered greater TD, high-acceleration, and

Table 2 Comparisons of match running performance between bottom- vs. top-ranked teams during the 2020 season of the Brazilian National 2nd Division League

\begin{tabular}{|c|c|c|c|c|c|c|}
\hline \multirow[t]{2}{*}{ Variables } & \multicolumn{2}{|l|}{ 1st Halves } & \multicolumn{2}{|l|}{ 2nd Halves } & \multicolumn{2}{|l|}{ Whole matches } \\
\hline & $\begin{array}{l}\text { Bottom-ranked } \\
\text { Team }\end{array}$ & $\begin{array}{l}\text { Top-ranked } \\
\text { Team }\end{array}$ & $\begin{array}{l}\text { Bottom-ranked } \\
\text { Team }\end{array}$ & $\begin{array}{l}\text { Top-ranked } \\
\text { Team }\end{array}$ & $\begin{array}{l}\text { Bottom-ranked } \\
\text { Team }\end{array}$ & $\begin{array}{l}\text { Top-ranked } \\
\text { Team }\end{array}$ \\
\hline $\mathrm{TD}(\mathrm{m})$ & $4944.5(567.5)$ & $5200.0(770.0)^{\mathrm{a}}$ & $4918.5(622.5)$ & $5160.0(770.0)^{\mathrm{a}}$ & $9892.0(1119.5)$ & $10330.0(1430.0)^{\mathrm{a}}$ \\
\hline $\operatorname{HSR}(\mathrm{m})$ & $496.0(266.2)$ & $519.0(859.0)$ & $473.5(267.7)$ & $480.0(322.0)$ & $984.5(518.5)$ & $1057.0(660.0)$ \\
\hline Number of Sprints & $16.0(9.0)$ & $17.0(10.0)$ & $15.5(9.0)$ & $16.0(9.0)$ & $32.0(18.0)$ & $34.0(21.0)$ \\
\hline High-acceleration (m) & $45.5(15.0)$ & $48.0(19.0)^{\mathrm{a}}$ & $42.0(13.0)$ & $46.0(17.0)^{\mathrm{a}}$ & $87.0(23.0)$ & $97.0(32.0)^{\mathrm{a}}$ \\
\hline High-deceleration (m) & $52.0(14.0)$ & $53.0(22.0)$ & $48.0(15.0)$ & $51.0(18.0)$ & $99.0(25.7)$ & $104.0(37.0)$ \\
\hline
\end{tabular}

The data are described by the median (interquartile range)

$\mathrm{TD}=$ Total distance covered; HSR $=$ High-speed running $\left(>18 \mathrm{~km} \mathrm{~h}^{-1}\right)$; High-acceleration $\left(>3 \mathrm{~m} \mathrm{~s}^{2}\right)$; High-deceleration $\left(<-3 \mathrm{~m} \mathrm{~s}^{2}\right)$; Number of sprints $\left(>25 \mathrm{~km} \mathrm{~h}^{-1}\right)$

${ }^{a}$ Top-ranked Team $>$ Bottom-ranked Team $(p<0.05)$ 


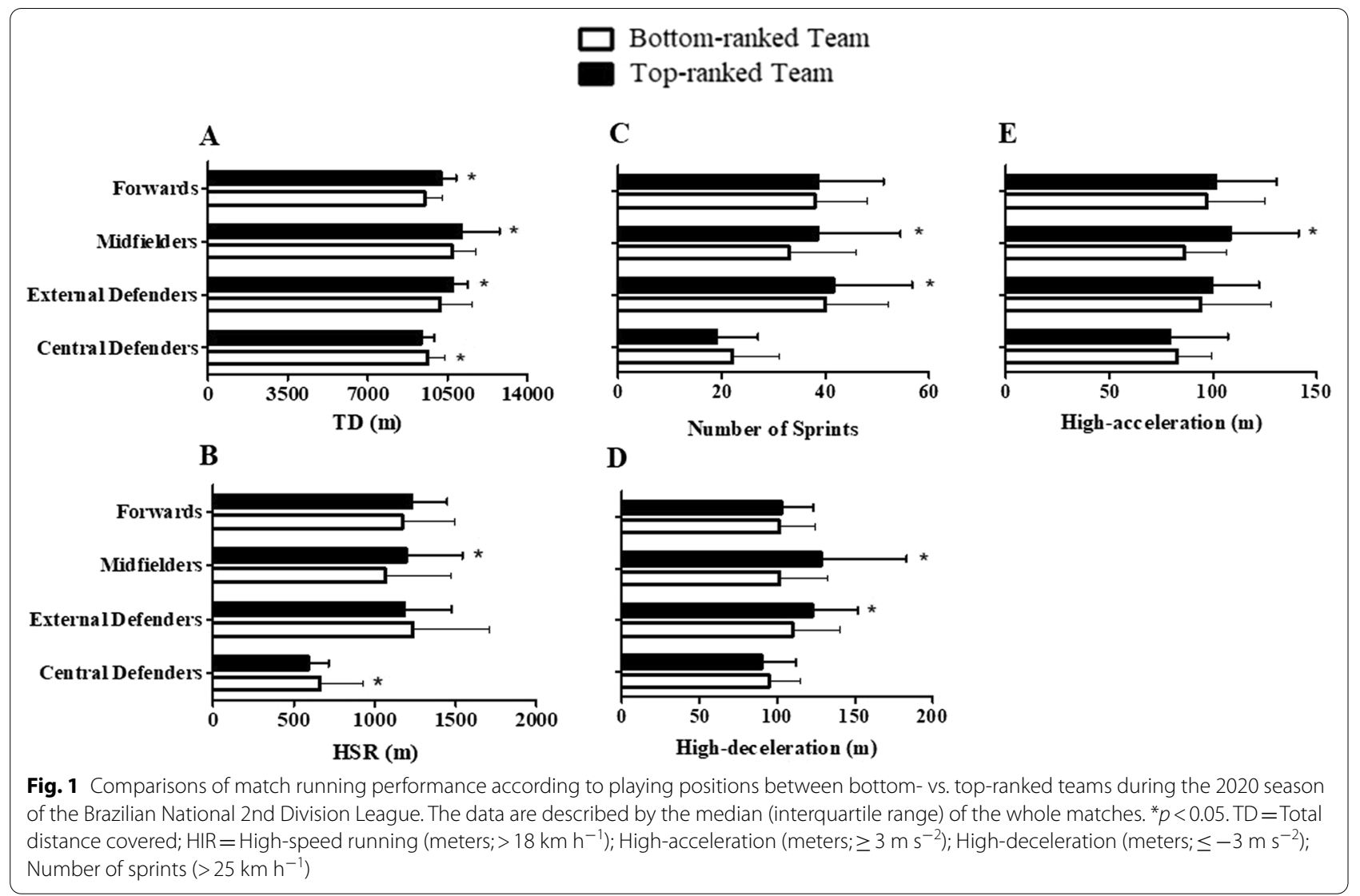

Table 3 Comparisons of match running performance according to match location between bottom- vs. top-ranked teams during the 2020 season of the Brazilian National 2nd Division League

\begin{tabular}{|c|c|c|c|c|}
\hline \multirow[t]{2}{*}{ Variables } & \multicolumn{2}{|c|}{ Bottom-ranked team } & \multicolumn{2}{|l|}{ Top-ranked team } \\
\hline & Home & Away & Home & Away \\
\hline $\mathrm{TD}(\mathrm{m})$ & $9916.0(1257.5)$ & 9829.5 (1123.0) & $10440.0(1310.0)^{\mathrm{a}}$ & $10290.0(1567.5)^{\mathrm{a}}$ \\
\hline $\operatorname{HSR}(\mathrm{m})$ & $1007.5(502.2)$ & $982.0(527.2)$ & $1081.0(715.0)$ & $1001.0(624.0)$ \\
\hline Number of sprints & $33.0(17.0)$ & $31.5(18.5)$ & $34.0(20.0)$ & $33.0(19.7)$ \\
\hline High-acceleration (m) & $86.0(24.5)$ & $88.0(23.0)$ & $95.0(33.0)$ & $97.5(29.0)^{\mathrm{a}}$ \\
\hline High-deceleration (m) & $98.0(25.7)$ & $100.0(25.7)$ & $105.0(35.0)^{\mathrm{a}}$ & $103.0(36.2)$ \\
\hline
\end{tabular}

The data are described by the median (interquartile range) of the whole matches

$\mathrm{TD}=$ Total distance covered; HSR $=$ High-speed running $\left(>18 \mathrm{~km} \mathrm{~h}^{-1}\right)$; High-acceleration $\left(>3 \mathrm{~m} \mathrm{~s}^{2}\right)$; High-deceleration $\left(<-3 \mathrm{~m} \mathrm{~s}^{2}\right) ;$ Number of sprints $\left(>25 \mathrm{~km} \mathrm{~h}^{-1}\right)$

${ }^{a}$ Top-ranked Team $>$ Bottom-ranked Team $(p<0.05) ; p<0.05$

high-deceleration than bottom-ranked team in loss matches $\left(p=0.004-0.007 ; \eta^{2}=\right.$ small; Table 5$)$.

\section{Discussion}

This study aimed to compare the match running performance between successful (top-ranked) and unsuccessful (bottom-ranked) professional soccer teams. The main findings were: (1) the top-ranked team covered greater
TD and high-acceleration than the bottom-ranked team in home and away matches, mainly due to midfielders (moderate effect size). Central defenders presented contrasting results (bottom-ranked team > top-ranked team; small effect size); (2) the matches against top-level opponents required high values of GPS-derived outputs only for the top-ranked team; (3) the match outcome was not influenced by running performance for both bottom- and 
Table 4 Comparisons of match running performance according to quality of opposition between bottom- vs. top-ranked teams during the 2020 season of the Brazilian National 2nd Division League

\begin{tabular}{|c|c|c|c|c|c|c|}
\hline \multirow[t]{2}{*}{ Variables } & \multicolumn{3}{|c|}{ Bottom-ranked team } & \multicolumn{3}{|l|}{ Top-ranked team } \\
\hline & vs. Bottom-level & vs. Intermediate-level & vs. Top-level & vs. Bottom-level & vs. Intermediate-level & vs. Top-level \\
\hline $\mathrm{TD}(\mathrm{m})$ & $10075.0(979.5)$ & $9941.0(1190.5)$ & $9643.5(1025.0)$ & $10120.0(1300.0)$ & $10340.0(1567.5)^{c}$ & $10,755.0(1305.0)^{c}$ \\
\hline $\operatorname{HSR}(\mathrm{m})$ & $991.0(549.5)$ & $1004.0(541.5)$ & $921.5(480.5)$ & $968.0(664.5)$ & $1056.0(637.0)$ & $1201.0(711.5)$ \\
\hline Number of Sprints & $33.0(16.5)$ & $32.0(18.0)$ & $31.0(16.5)$ & $29.0(19.5)$ & $34.0(20.7)$ & $40.0(16.5)^{b}$ \\
\hline High-acceleration (m) & $91.0(29.5)$ & $88.0(23.5)$ & $83.5(24.5)$ & $90.0(37.5)$ & $95.0(30.0)$ & $107.5(30.5)^{b, c}$ \\
\hline High-deceleration (m) & $98.0(26.5)$ & $101.0(26.0)$ & $95.0(24.2)$ & $102.0(41.5)$ & $102.0(36.5)$ & $117.0(33.0)^{c}$ \\
\hline
\end{tabular}

The data are described by the median (interquartile range) of the whole matches

$\mathrm{TD}=$ Total distance covered; HSR $=$ High-speed running $\left(>18 \mathrm{~km} \mathrm{~h}^{-1}\right)$; High-acceleration $\left(>3 \mathrm{~m} \mathrm{~s}^{2}\right)$; High-deceleration $\left(<-3 \mathrm{~m} \mathrm{~s}^{2}\right)$; Number of sprints $\left(>25 \mathrm{~km} \mathrm{~h}^{-1}\right)$

${ }^{a}$ vs. Top-level > vs. Intermediate-level $(p<0.05)$

${ }^{\mathrm{b}}$ vs. Top-level $>$ vs. Bottom-level $(p<0.05)$

${ }^{c}=$ Top-ranked team $>$ Bottom-ranked team $(p<0.05)$

Table 5 Comparisons of match running performance according to match outcome between bottom- vs. top-ranked teams during the 2020 season of the Brazilian National 2nd Division League

\begin{tabular}{|c|c|c|c|c|c|c|}
\hline \multirow[t]{2}{*}{ Variables } & \multicolumn{3}{|c|}{ Bottom-ranked team } & \multicolumn{3}{|l|}{ Top-ranked team } \\
\hline & Loss & Draw & Win & Loss & Draw & Win \\
\hline $\mathrm{TD}(\mathrm{m})$ & 9657.5 (1176.0) & $10070.5(1067.2)$ & $10053.0(1080.0)$ & $10330.0(1600.0)^{c}$ & $10250.0(1040.0)$ & $10370.0(1520.0)$ \\
\hline $\operatorname{HSR}(\mathrm{m})$ & $975.0(519.5)$ & $987.0(451.2)$ & $1056.0(590.2)$ & $1069.0(640.0)$ & $1068.0(660.5)$ & $1031.0(609.0)$ \\
\hline Number of Sprints & $31.5(17.0)$ & $33.0(17.0)$ & $33.5(19.7)$ & $37.0(25.0)$ & $35.0(18.5)$ & $30.0(19.5)$ \\
\hline High-acceleration (m) & $85.5(23.5)$ & $86.5(19.2)$ & $90.5(33.2)$ & $100.0(35.0)^{c}$ & $98.0(29.0)$ & $92.0(30.0)$ \\
\hline High-deceleration (m) & $98.5(24.5)$ & $100.5(25.7)$ & $100.5(31.2)$ & $104.0(40.0)^{c}$ & $105.0(33.5)$ & $100.0(42.0)$ \\
\hline
\end{tabular}

The data are described by the median (interquartile range) of the whole matches

$\mathrm{TD}=$ Total distance covered; HSR $=$ High-speed running $\left(>18 \mathrm{~km} \mathrm{~h}^{-1}\right)$; High-acceleration $\left(>3 \mathrm{~m} \mathrm{~s}^{2}\right)$; High-deceleration $(<-3 \mathrm{~m} \mathrm{~s})^{2}$; Number of sprints $\left(>25 \mathrm{~km} \mathrm{~h}^{-1}\right)$

${ }^{a}$ vs. Win $>$ Draw $(p<0.05)$

${ }^{\mathrm{b}}$ Win $>$ vs. Loss $(p<0.05)$

${ }^{c}=$ Top-ranked team $>$ Bottom-ranked team $(p<0.05)$

top-ranked teams. However, the top-ranked team presented greater running demands than the bottom-ranked team in loss matches.

Match running performance was previously investigated in several countries [3]. In general, players covered an average of $\sim 9$ to $11 \mathrm{~km}$ during the matches of different Leagues, including Serie A-Italy [29], EkstraklasaPoland [30], League 1-France [31], Eliteserien-Norway [7], La Liga-Spain [32], Premier League-England [33], Croatian League-Croatia [34], or 2nd Division of the Greek League [35]. In our study, both teams presented running outputs similar to the Brazilian elite-level (1st Division: $\sim 10 \mathrm{~km} \mathrm{[36]).} \mathrm{Specifically} \mathrm{related} \mathrm{to} \mathrm{HSR,}$ top- and bottom-ranked teams analyzed in this study presented similar values $\left(\sim 1000 \mathrm{~m}\right.$ above $\left.18.0 \mathrm{~km} \mathrm{~h}^{-1}\right)$ between them and compared to the previous edition (season 2019) of the Brazilian National 2nd Division League [23]. The speed thresholds used to consider HSR in the current study $\left(>18.0 \mathrm{~km} \mathrm{~h}^{-1}\right)$ hinder direct comparisons between our data and those observed in elite-level domestic Leagues around the world ( $\sim 830 \mathrm{~m}$ above $19.1 \mathrm{~km} \mathrm{~h}^{-1}$ or $\sim 950 \mathrm{~m}^{2}$ above $19.8 \mathrm{~km} \mathrm{~h}^{-1}$ ) [3].

In $2017 / 18$ Serie A League (Italy), the teams within the first four positions showed a lower percentage of running activity, a higher rate of jogging and sprint activities than the teams ranked fifth and below in the same competition [37]. Similar results were found in Chinese Super League [38]. In contrast, previous studies in La Liga (season 2013/14) [20] and German Bundesliga (season 2012/13) [21] reported that both successful and unsuccessful teams presented the same running requirements in total distance covered and total distance or number of activities in HSR (La Liga: meters above 21 and $24 \mathrm{~km}^{\prime \prime} \mathrm{h}^{-1}$; German Bundesliga: frequency of running

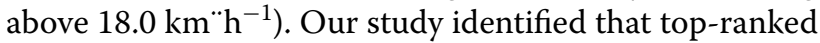
team covered greater TD and high-acceleration than the bottom-ranked team in home and away matches. These results suggest that high volume of distance covered, and mechanical load were related to success. In general, the contrasting findings between our study (Brazilian 
National 2nd Division) and previous findings (e.g., La Liga, German Bundesliga) suggest that the influence of the match running performance on a team's success depends, at least in part, on the disputed League. Specific reasons for this difference can be better investigated in further studies (e.g., comparisons of the physical fitness tests between successful and unsuccessful Brazilian soccer teams in the same competition). In addition, we verified that the magnitude of the differences of the match running performance between top- and bottom-ranked teams were position-dependent.

In English Premier League (season 2003/2004; 2004/2005; 2005/2006), external midfielders of middleand bottom-ranked teams completed greater HSR (large effect size) than top-ranked teams [19]. In our study, central defenders of the bottom-ranked team presented higher TD and HSR than top-ranked team (small effects sizes). In contrast, we observed that midfielders of the top-ranked team covered greater TD and high acceleration than bottom-ranked (moderate effects sizes). Therefore, despite the previous evidence of small effect size in the comparisons of running performance between topand bottom-ranked teams (grouped players), moderateto-large effects were computed when considered playing positions. Our results suggest that some positional rules should be physically prepared to compete in top- (midfielders) and bottom-ranked (central defenders) Brazilian soccer teams. These differences are possibly caused by the more defensive and offensive requirements during the competition in the bottom- and top-ranked teams, respectively.

Research examining contextual factors such as match location, quality of opposition, and match outcome demonstrates these have an impact on the running demands of players $[8,12,33]$. In general, home matches played against top-ranked teams and with a win resulted in greater running outputs [13, 29, 39]. In addition, elitelevel players usually performed less HSR when winning than when they were losing [40]. In our study, these contextual factors did not promote independent effects on running performance in both top- and bottom-ranked teams. This findings are in line with previous study during the 2019 season of the Brazilian National 2nd Division League [23]. In addition, the current study observed that independent of the match location, top-ranked team covered greater distances than bottom-ranked team, although with small effect sizes. However, the matches against top-level opponents required high values of high-acceleration and number of sprints only for the top-ranked team, possibly indicating that need to remain among the top-four required more physical effort from the players. These results suggest that players moderate their maximal physical capacity during the match based upon the match characteristics in combination with the opposition $[8,38]$.

The previous studies in Brazilian National 4th and 3rd Division reported greater match running performance (e.g., TD, HSR) when the teams won in comparison with matches it lost [39, 41]. In the Brazilian National 2nd Division (season 2019), both win and loss matches presented the same running requirements [23], suggesting more stable running outputs in higher-division independent of the match outcome. However, these studies did not consider the team's final ranking. In our study, the top-ranked team presented greater TD, high acceleration, and high deceleration than the bottom-ranked team in loss matches (small effect size). The descriptive analysis between win, draw, and loss matches within groups showed that the top-ranked team presented more stable running outputs (e.g., TD-loss $=10,330.0 \mathrm{~m}$ vs. TD-win $=10,370.0 \mathrm{~m}$ ) compared to the bottom-ranked team during the competition (e.g., TD-loss $=9567.5 \mathrm{~m}$ vs. TD-win $=10,053.0)$ (see Table 5). We might suppose that the successful team in the league utilizes their physical capacity independent of the match outcome, and when a team is lower in the league their reduce the distances covered and mechanical load when losing the matches. In addition, overall technical-tactical effectiveness probably has a greater impact on match outcome and team's final League ranking than running performance in elite divisions [1]. For example, the players of the champion team of the 2018 FIFA World Cup (France) and one of the teams with the worst performance (Panama) had a similar match running performance $(\mathrm{TD}=\sim 10 \mathrm{~km} ; \sim 10 \%>2$ $\left.0 \mathrm{~km} \mathrm{~h}^{-1}\right)$. In contrast, French players presented higher levels of interconnectivity between close teammates (greater cooperation) [42].

This study has some limitations that should be recognized. The major limitation was the analyzed data from only successful and one unsuccessful team. The running performance of one team can be affected by some specific factors like style of the play or tactical formation [12]. However, both the analyzed teams presented similar playing styles and tactical formation over the season. Second, the lack of analysis of technical-tactical performance indicators (e.g., notational analysis, collective dynamics, tactical behavior) can be considered other limitation. Third, the design was conducted only in one season. Further studies should investigate the characteristics of successful and unsuccessful teams in multiple seasons and with a holistic data approach (e.g., physical, and technical-tactical).

However, this study advances in some aspects from previous literature about this topic. For example, we considered independent and interactive effects of a myriad of independent measures (i.e., playing positions, 
match location, quality of opposition, match outcome). Furthermore, to the best of our knowledge, this is the first study that provides information regarding match running performance of successful and unsuccessful teams in Brazilian soccer. These results can aid coaches and practitioners to understand the set of physical variables that better discriminates successful and unsuccessful professional soccer teams, including aspects from the playing position and context that matters.

\section{Conclusions}

This study demonstrated that changes in running performance during match-play are related to several factors, such as the team's ranking, the playing positions, the match location, the quality of opposition, and the match outcome. Specifically, mainly midfielders of the topranked team completed greater running distances than their counterparts of the bottom-ranked team, both in home and away matches. In contrast, central defenders of the bottom-ranked team presented greater running outputs (i.e., TD, HSR) than their counterparts of the topranked team. Our results also showed that the quality of opposition influenced only the top-ranked team, which matches against top-level opponents required high values of running performance. Finally, the top-ranked team presented greater TD, high acceleration, and high deceleration than the bottom-ranked team in loss matches. These findings suggest that running performance was an important aspect to discriminate top- and bottomranked teams in the Brazilian context.

In addition, strategy and technical-tactical dimensions probably have a greater impact on results and final ranking than running performance. Further studies should investigate these aspects in Brazilian leagues. Therefore, inferences about the cause-effect between match running demands and competitive standard/ match outcome should be viewed with caution.

\footnotetext{
Abbreviations

GPS: Global positioning systems; IMUs: Inertial sensor units; TD: Total distance covered; HSR: Total distance covered under high-speed running; Acc: Total distance covered under high acceleration; Dec: Total distance covered under high deceleration; A.U.: Arbitrary units.
}

\section{Acknowledgements}

The authors would like to thank the coaching staff and players of the Botafogo Football Club S/A (Ribeirão Preto, Brazil) and Juventude Sport Club (Caxias do Sul, Brazil).

\section{Authors' contributions}

Conceptualization, R.A., E.R., A.P., T.S.M.; methodology, R.A., E.R., A.P., G.G., M.N., T.S.M., H.N.; formal analysis, R.A., L.G.G., M.G., G.G., M.N. investigation, R.A., L.G.G., M.G., F.Y.N., H.N., G.G., M.N.; writing-original draft preparation, R.A. F.Y.N.; writing-review and editing, all authors. All authors have read and agreed to the final version of the manuscript.
Funding

This research received no external funding.

\section{Availability of data and materials}

The datasets generated during and analyzed during the current study are available from the corresponding author on reasonable request.

\section{Declarations}

\section{Ethical approval}

The training coaches of the club, after obtaining permission from the relevant authorities and the head coach of the club, conducted this research. Before commencing the study, it also received the approval of the research ethics committee from the University of São Paulo (61884716.9.0000.5659).

\section{Consent for publication}

Not applicable.

\section{Informed consent}

All players were informed of the purpose of the study before completing the informed consent. All stages of this study were carried out based on the ethical principles in the Helsinki Declaration.

\section{Competing interests}

The authors declare that they have no competing interests.

\section{Author details}

${ }^{1}$ LabSport, Department of Sports, Center of Physical Education and Sports, Federal University of Espírito Santo, Vitória, Brazil. ${ }^{2}$ School of Physical Education and Sport of Ribeirão Preto, University of São Paulo, Ribeirão Preto, Brazil. ${ }^{3}$ Department of Performance Analysis, Botafogo Football Club, Ribeirão Preto, Brazil. ${ }^{4}$ Department of Performance Analysis, Juventude Sport Club, Caxias do Sul, Brazil. ${ }^{5}$ Catapult Group International Ltd., Melbourne, Australia. ${ }^{6}$ Department of Exercise Physiology, Faculty of Sport Sciences, University of Isfahan, 81746-7344 Isfahan, Iran. ${ }^{7}$ Sports Scientist, Sepahan Football Club, 81887-78473 Isfahan, Iran. ${ }^{8}$ Research Center in Sports Sciences, Health Sciences and Human Development (CIDESD), University Institute of Maia (ISMAI), 4475-690 Maia, Portugal.

Received: 21 April 2021 Accepted: 11 August 2021

Published online: 17 August 2021

\section{References}

1. Carling C. Interpreting physical performance in professional soccer match-play: should we be more pragmatic in our approach? Sports Med. 2013;43:655-63. https://doi.org/10.1007/s40279-013-0055-8.

2. Carling C, Bloomfield J, Nelsen L, Reilly T. The role of motion analysis in elite soccer: contemporary performance measurement techniques and work rate data. Sports Med. 2008;38:839-62. https://doi.org/10.2165/ 00007256-200838100-00004.

3. Hands DE, Janse de Jonge X. Current time-motion analyses of professional football matches in top-level domestic leagues: a systematic review. Int J Perform Anal Sport. 2020;20:747-65. https://doi.org/10.1080/ 24748668.2020.1780872.

4. Buchheit M, Simpson BM. Player-tracking technology: half-full or halfempty glass? Int J Sports Physiol Perform. 2017;12(Suppl 2):S235-41. https://doi.org/10.1123/ijspp.2016-0499.

5. Castillo D, Raya-González J, Weston M, Yanci J. Distribution of external load during acquisition training sessions and match play of a professional soccer team. J Strength Cond Res. 2019; https://doi.org/10.1519/JSC. 0000000000003363.

6. Clemente FM, Silva R, Ramirez-Campillo R, Afonso J, Mendes B, Chen Y-S. Accelerometry-based variables in professional soccer players: comparisons between periods of the season and playing positions. Biol Sport. 2020;37:389.

7. Dalen T, Jørgen I, Gertjan E, Havard HG, Ulrik W. Player load, acceleration, and deceleration during forty-five competitive matches of elite soccer. J Strength Cond Res. 2016;30:351-9. 
8. Lago-Peñas $C$. The role of situational variables in analysing physical performance in soccer. J Hum Kinet. 2012;35:89-95.

9. Aquino R, Vieira LHP, Carling C, Martins GHM, Alves IS, Puggina EF. Effects of competitive standard, team formation and playing position on match running performance of Brazilian professional soccer players. Int J Perform Anal Sport. 2017;17:695-705

10. Sydney MG, Ball N, Chapman D, Wollin M, Mara JK. Does competition standard and player position influence the match-play physical demands of Australian elite youth male soccer players within a single squad? Int J Sports Sci Coach. 2021;16:360-9.

11. Buchheit M, Allen A, Poon TK, Modonutti M, Gregson W, Di Salvo V. Integrating different tracking systems in football: multiple camera semiautomatic system, local position measurement and GPS technologies. J Sports Sci. 2014;32:1844-57. https://doi.org/10.1080/02640414.2014. 942687.

12. Paul DJ, Bradley PS, Nassis GP. Factors affecting match running performance of elite soccer players: shedding some light on the complexity. Int J Sports Physiol Perform. 2015;10:516-9.

13. Aquino R, Carling C, Vieira LHP, Martins G, Jabor G, Machado J, et al. Influence of situational variables, team formation, and playing position on match running performance and social network analysis in brazilian professional soccer players. J Strength Cond Res. 2020;34:808-17.

14. Wisloeff U, Helgerud JAN, Hoff JAN. Strength and endurance of elite soccer players. Med Sci Sports Exerc. 1998;30:462-7.

15. Apor P. Successful formulae for fitness training. In: Reilly T, Lees A, Davids K, et al., editors. Science and football. London: E\&FN Spon; 1988. p. 95-107.

16. Di Salvo V, Pigozzi F, González-Haro C, Laughlin MS, De Witt JK. Match performance comparison in top English soccer leagues. Int J Sports Med. 2013;34:526-32.

17. Bradley PS, Carling C, Diaz AG, Hood P, Barnes C, Ade J, et al. Match performance and physical capacity of players in the top three competitive standards of English professional soccer. Hum Mov Sci. 2013;32:808-21.

18. Rampinini E, Impellizzeri FM, Castagna C, Coutts AJ, Wisløff U. Technical performance during soccer matches of the Italian Serie A league: Effect of fatigue and competitive level. J Sci Med Sport. 2009;12:227-33.

19. Di Salvo V, Gregson W, Atkinson G, Tordoff P, Drust B. Analysis of high intensity activity in Premier League soccer. Int J Sports Med. 2009;30:205-12.

20. Asian Clemente JA, Requena B, Jukic I, Nayler J, Hernández AS, Carling C. Is physical performance a differentiating element between more or less successful football teams? Sports. 2019;7:216.

21. Hoppe MW, Slomka M, Baumgart C, Weber H, Freiwald J. Match running performance and success across a season in German Bundesliga soccer teams. Int J Sports Med. 2015;36:563-6.

22. Brito J, Hertzog M, Nassis GP. Do match-related contextual variables influence training load in highly trained soccer players? J Strength Cond Res. 2016;30:393-9.

23. Gonçalves LGC, Kalva-Filho CA, Nakamura FY, Rago V, Afonso J, Bedo BLDS, et al. Effects of match-related contextual factors on weekly load responses in professional Brazilian soccer players. Int J Environ Res Public Health. 2020;17:1-13.

24. Halouani J, Ghattasi K, Bouzid MA, Rosemann T, Nikolaidis PT, Chtourou $\mathrm{H}$, et al. Physical and physiological responses during the stop-ball rule during small-sided games in soccer players. Sports. 2019;7:117.

25. Jennings D, Cormack S, Coutts AJ, Boyd LJ, Aughey RJ. Variability of GPS units for measuring distance in team sport movements. Int J Sports Physiol Perform. 2010;5:565-9.

26. Castagna C, Varley M, Póvoas SCA, D'Ottavio S. Evaluation of the match external load in soccer: methods comparison. Int J Sports Physiol Perform. 2017;12:490-5. https://doi.org/10.1123/ijspp.2016-0160.
27. Fritz CO, Morris PE, Richler JJ. Effect size estimates: current use, calculations, and interpretation. J Exp Psychol Gen. 2012;141:2.

28. Cohen J. Statistical power analysis for the behavioral sciences. Cambridge: Academic Press; 2013.

29. Rampinini E, Coutts AJ, Castagna C, Sassi R, Impellizzeri FM. Variation in top level soccer match performance. Int J Sports Med. 2007;28:1018-24.

30. Andrzejewski M, Pluta B, Konefal M, Chmura P, Chmura JAN. Analysis of the motor activities of professional Polish soccer players. Polish J Sport Tour. 2016;23:196.

31. Carling C, Bradley P, McCall A, Dupont G. Match-to-match variability in high-speed running activity in a professional soccer team. J Sports Sci. 2016;34:2215-23. https://doi.org/10.1080/02640414.2016.1176228.

32. Castellano J, Blanco-Villaseñor A, Alvarez D. Contextual variables and time-motion analysis in soccer. Int J Sports Med. 2011;32:415-21.

33. Bradley PS, Noakes TD. Match running performance fluctuations in elite soccer: indicative of fatigue, pacing or situational influences? J Sports Sci. 2013;31:1627-38

34. Modric T, Versic S, Sekulic D, Liposek S. Analysis of the association between running performance and game performance indicators in professional soccer players. Int J Environ Res Public Health. 2019;16:4032.

35. Metaxas TI. Match running performance of elite soccer players: $V 02$ max and players position influences. J Strength Cond Res. 2021;35:162-8. https://doi.org/10.1519/JSC.0000000000002646.

36. Barros RML, Misuta MS, Menezes RP, Figueroa PJ, Moura FA, Cunha SA, et al. Analysis of the distances covered by first division brazilian soccer players obtained with an automatic tracking method. J Sports Sci Med. 2007:6:233-42.

37. Longo UG, Sofi F, Candela V, Ambrogioni LR, Pagliai G, Massaroni C, et al. The influence of athletic performance on the highest positions of the final ranking during 2017/2018 Serie A season. BMC Sports Sci Med Rehabil. 2021;13:1-8.

38. Yang G, Leicht AS, Lago C, Gómez M-Á. Key team physical and technical performance indicators indicative of team quality in the soccer Chinese super league. Res Sport Med. 2018;26:158-67.

39. Aquino R, Munhoz Martins GH, Palucci Vieira LH, Menezes RP. Influence of match location, quality of opponents, and match status on movement patterns in Brazilian professional football players. J Strength Cond Res. 2017:31:2155-61. https://doi.org/10.1519/JSC.0000000000001674.

40. Lago C, Casais L, Dominguez E, Sampaio J. The effects of situational variables on distance covered at various speeds in elite soccer. Eur J Sport Sci. 2010;10:103-9.

41. Aquino R, Carling C, Palucci Vieira LH, Martins G, Jabor G, Machado J, et al. Influence of situational variables, team formation, and playing position on match running performance and social network analysis in brazilian professional soccer players. J Strength Cond Res. 2020;34:808-17.

42. Aquino R, Machado JC, Manuel Clemente F, Praça GM, Gonçalves LGC, Melli-Neto B, et al. Comparisons of ball possession, match running performance, player prominence and team network properties according to match outcome and playing formation during the 2018 FIFA World Cup. Int J Perform Anal Sport. 2019;19:1026-37. https://doi.org/10.1080/24748 668.2019 .1689753$.

\section{Publisher's Note}

Springer Nature remains neutral with regard to jurisdictional claims in published maps and institutional affiliations. 